Cost to N.H.S. of Social Outcasts with Organic Disease

R. A. S. Keighley, M.B., and others; D. Tidmarsh, M.B.................... 389 SI Units

B. H. Hand, F.R.C.S., and others. ....... 389

Treatment of Falciparum Malaria

L. J. Bruce-Chwatt, F.R.C.P. . . . . . . . . 390

Oral Contraceptives and Myocardial Infarction

J. S. Robertson, M.F.C.M.; Mavis W. M

Stratford, M.R.C.s................391

Intracardiac Short Circuit

R. Sutton, M.R.C.P., and others......... 391

Hormone Patterns in Anorexia Nervosa

J. M. Tanner, F.R.c.P.; B. Alderman,

M.R.C.o.g., and M. Burke...........391
Serum $\alpha$-Fetoprotein in Cystic Fibrosis

J. C. Wallwork, PH.D., and others; D. J. H.

Brock, PH.D., and others; J. A. Smith, M.D...391

Manipulation in Treatment of Low Back

Pain

J. H. Ebbetts, M.R.c.s. . . . . . . . . 393

Approved Names

J. W. Dundee, F.F.A.R.C.S. . . . . . . . . . . 393

Tepid Sponging in Pyrexia

A. Aynsley-Green, M.R.C.P., and D. Pickering,

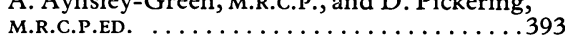

Consultant Negotiations

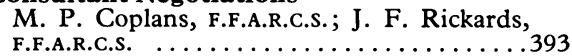

Practice Premises

A. Elliott, M.R.C.G.P. . . . . . . . . . . . 394
Consultants' Contract Shopping List

R. S. Morton, F.R.C.P.ED............. 394

Health Care Planning Teams

C. P. Vellenoweth, A.M.B.I.M., and J. R.

Gibson, PH.D., M.F.C.M..............394

Consultants' Fees for Dental Anaesthetics

R. L. McMillan, F.F.A.R.C.S.......... 395

Fees for Insurance Reports

D. Hartley, PH.D................... 395

Points from Letters Related Ancillary Staff (B. J. Stafford); Age Limit for Seniority Payments (D. M. O'Connor); Manipulation in Treatment of Low Back Pain (R. C. B. Barbor, A. H. G. Murley, R. Burns, A. R. Montgomery)................. 395
Correspondents are urged to write briefly so that readers may be offered as wide a selection of letters as possible. So many are now being received that the omission of some is inevitable. Letters should be signed personally by all their authors.

\section{Cost to N.H.S. of Social Outcasts with Organic Disease}

SIR,-Drs. N. J. Cooke and I. W. B. Grant (19 April, p. 132) are probably not to blame for the interest and comment their communication has aroused in the national press. The facts they present highlight a real social and medical problem; the interpretation of the facts is more arguable.

Their single patient spent 554 of his 1000 inpatient days in one hospital and 796 in only two hospitals over seven years. This does not quite fit the picture painted in their introductory paragraph. The figures also suggest that the record system of some at least of the institutions concerned, coupled with awareness of the problem on the part of admitting officers, might have been adequate to prevent admission on occasions when his symptoms could have been managed on an outpatient basis. Their facts are also an indiotment of "routine investigations," to which their patient was "inevitably subjected."

However, our main concern is to highlight the fact that this group of homeless men usually have great difficulty in obtaining primary medical care. They rarely register with a general practitioner and usually are not encouraged to do so. The result is no continuity of care, with the consequent attendance at a variety of casualty depantments and admission to a variety of hospitals.

There is no easy solution to this formidable problem but at least we need to recognize its presence. In Leeds a group of volunteer doctors run a G.P. service for the homeless men who are cared for by St. George's Crypt. This service, apart from dealing with a great deal of minor suffering -bronchitis, piles, painful feet, etc.-is also able to provide maintenance therapy for epileptics, bronchitics, depressives, etc. and in addition is able to detect at any early stage and refer to appropriate sympathetic consultants previously undiagnosed mental and physical illness, including drink problems. Incidentally we enjoy a good relation- ship with our local chest physician, with whom we work closely. This voluntary service, by attempting to meet these needs, is able to control to some extent hospital admissions of this type of patient and thereby save the N.H.S. considerable sums of money.

We believe that primary medical care should be supplied in those places where such men congregate-hostels, reception centres, and shelters such as ours-and would plead with local authorities, community physicians, and family practitioner committees to exert themselves to overcome the bureaucracy that usually prevents such a service developing and inhibits the service at its point of application-that is, the doctor-patient encounter.-We are, etc.,

\section{R. A. S. KeIGHLEY} H. Marshall Williams Medical Officers Don Paterson

St. George's Crypt, Warden

Great George Street,

SIR,-However much one may disagree with the tone of the anticle by Drs. N. J. Cooke and I. W. B. Grant (19 April, p. 132) there is no doubit that the authors have drawn attention to a significant social and medical problem, though it is one which has been with us for a very long time.

In 1966 a paper from the depantment of general practice of Edinburgh University 1 drew attention to the very considerable morbidity of common lodging-house users and the high proportion of their consultations which led to referral to hospital. The authors suggested that "some attention might profitably be given to the problems of communication between hospital outpatient depantments, as well as between these depantments and the general practitioner or voluntary agencies in the community, so as to minimize unnecessary referral and unnecessary repetition of examinations and tests." It would appear that these suggestions have not borne fruit in Edinburgh.

In London the prototype for a better system has been in existence for 20 years. Many homeless and destitute men with physical illness come to the Camberwell Reception Centre specifically to avail themselves of the services of the visiting medical officers and the sick-bay. $X$-ray and pathology services are provided by local hospitals and it is probable that the patient described by Drs. Cooke and Grant could have been treated quite adequately in these facilities. Unfortunately these few beds are under pressure, and for the lodging-house population the problem of access to medical care remains, as the voluntary organizations continue to remind us. ${ }^{2}$ This need was also uncovered in a recent survey of the homeless destitute men at the Camberwell Reception Centre, ${ }^{3}$ the clients of which are drawn largely from common lodging-house users. It was found that the mentally ill and physically handicapped were retained in the centre in most unsuitable surroundings for long periods for want of proper alternative facilities. It was recommended, inter alia, that "all common lodging-houses should have a general practitioner service available to all users and large common lodginghouses should have both clinic and sick-bay facilities." Surely this is not an impossible aspiration?-I am, etc.,

Broadmoor Hospital,

DAvid TIDMARSH Crowthorne, Berks

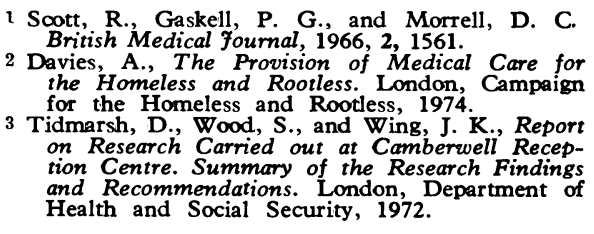

\section{SI Units}

SIR,-The Department of Health and Social Security has now circulated to regional and area health authorities, family practitioner committees, and boards of governors advice 
on the introduction of SI units into medicine (HSC(IS)140). Few clinicians seem to be aware that it is proposed to adopt this system throughout the N.H.S. by the end of 1975.

It is pertinent to consider what study of benefit balanced against the risk of patients was made before coming to this decision. The D.H.S.S. document actually states: "Measurements throughout clinical medicine . . require special attention for reasans of safety [our italics]. Consequently . . . international agreement has been reached on the need to utilize . . . SI for this purpose."

One might inquire what body of clinicians - who are closely concerned with the safety problems involved in medical measurement $\rightarrow$ was consulted about the introduction of these units. The answer, again according to the D.H.S.S. circular, is a working panty composed of biochemists, pathologists, and physicists. We are informed that their report was circulated to "medical . . . organizations concerned" and that "their comments have been taken into account." It would be helpful to know which organizations were so honoured and what methods of consultation they adopted. One could hardly expeot bioahemists and physicists to be familiar with the bedside problems facing doctors and nurses.

Though the international system (SI) of units has great importance in some fundamental sciences, one cannot see any practical benefit acomuing from its introduction into clinical medicine. In panticular the alteration of the unit of measurement of amounts of dissolved substance to the mole seems to be pointless, as well as scientifically highly questionable, when one considers the composition of biological fluids and their modes and sites of interaction.

We are seriously concerned about the dangers which may result to patients from the introduction of this system. The document states that "the safety of patients must be paramount" and goes on to say that the possibility of mistakes must be recognized. It suggests that a measure of independent checks will deal with this danger. A revealing example of the value of "independent checks" was demonstrated recently in the correspondence columns of the B.M.F. (30 November 1974 , p. 531). Here four ohemical pathologists, who had published a paper and a subsequent letter in the B.M.f., had to write again to point out that they had made an enror relating to SI units in their caloulations. These calculations had presumably been checked by the four authons on two oocasions, by the subeditor, referee, and perhaps a statistician as well, and yet a gross error oocurred. It is even more relevant to note that the paper referred to came from a reputable depantment of chemical pathology

Other disadvantages of the SI system of units in practice have been well described by With ${ }^{1}$ after several years' experience in Denmark.

We feel that these units cannot be introduced without risk to patients and that, whatever educational programme is devised, there will, for a long time to come, be a problem for recent arrivals - both medical and nursing - from developing countries to whom these units are unfamiliar. The danger of confusion when interpreting measurements of blood glucose and blood urea is particularly serious. The problem is easy for those who are remote from patient care. We, however, can see no benefits and only dangers from the introduction of SI units. We feel we must protect our medical and nursing staff from ariticism when errors, which we consider are unavoidable with the introduction of these units, occur. Some of these errors will lead to fatalities. In that case a copy of this letter, which is also being sent to the area health authorities, the regional health authority, and the D.H.S.S., will be produced in any coroner's count or when any other legal proceedings take place which may involve accusations of negligence against a doctor or nurse. We wish to make clear that this notation has been imposed from above, that we disapprove of it on grounds of risk to patients, and that we cannot accept responsibility for errors which cocur as a result of its introduction.

We consider from a purely practical point of view that the shontage of paper and printers' time, let alone the enormous cost of reprinting forms and alterations to existing equipment, will present a real problem. The costs will have to be catered for out of existing budgets.

In discussions we have found that many clinicians throughout the country have expressed similar concern to that which has been voiced in this letter. Their concern has not been allayed by the soothing noises emanating from members of the original working panty under the aegis of the Royal College of Pathologists. We would welcome the views of other regional medical committees on the dangers associated with the introduction of this notation.-We are, etc.,

$$
\begin{array}{r}
\text { BERNARD H. HAND } \\
\text { Chairman, } \\
\text { Regional Medical (Advisory) Committe, } \\
\text { East Anglian R.H.A. } \\
\text { B. B. MILSTEIN } \\
\text { Chairman, } \\
\text { Cambridgeshire Area Medical Committee } \\
\text { J. B. AGATE } \\
\text { Chairman, } \\
\text { Suffolk Area Medical Committee } \\
\text { H. DE C. BAKER } \\
\text { Chairman, } \\
\text { Norfolk Area Medical Committee }
\end{array}
$$
1 With, T. K., Lancet, 1974, 2, 1315.

***The working panty's detailed recommendations for the introduction of SI units for the reporting of results obtained in hospital laboratories in the U.K. were referred for comment to the Royal College of Physicians, Royal College of Surgeons, Royal College of Obstetricians and Gynaecologists, Royal College of General Practitioners, Royal College of Psychiatrists, Faculty of Anaesthetists, Faculty of Community Medicine, British Medical Association, British Institute of Radiology, Faculty of Radiology, and Joint Consultants Committee and to dental, nursing, and pharmaceutical organizations.-ED., B.M.f.

\section{Treatment of Falciparum Malaria}

SIR,-The paper by Col. A. P. Hall and others (5 April, p. 15) on the value of clindamycin in malaria calls for comment if only to underline the potential dangers of using some new antibiotics for the treatment of falciparum infections in those parts of the world where resistance of plasmodia to 4-aminoquinolines has been demonstrated. Acute colitis presenting as severe and persistent diarrhoea has been observed not infrequently during clindamycin treatment and one wonders if this compound, even at half the usual dosage, has any place for treatment of falciparum malaria when sulfadoxine with pyrimethamine shows a good curative effect. The trend of introducing some potent, new antibiotics for the treatment of falciparum malaria would have been justified if we had no other alternatives and if these compounds could be used with a reasonable degree of safety. However, both these criteria are still wanting with regard not only to the lincomycin group of antibiotics, to which clindamycin belongs, ${ }^{1}$ but also to the tetracyclines, the use of which was the subject of a leading anticle ${ }^{2}$ and of subsequent correspondence three years ago.

Colvell et $a l .^{3}$ showed that the combination of quinine with tetracycline was of some value for the treatment of falciparum malaria in Thailand, and Rieckmann et al. ${ }^{4}$ described a similar synergistic effect of amodiaquine and tetracycline against two strains of Plasmodium falciparum from Vietnam. While these studies are of interest, the side effects of tetracyclines must not be treated lightly. Because of its systemic anabolic action tetracycline will often increase azotaemia in any patient with renal impairment. It may also cause liver damage and gastrointestinal troubles, besides such sequelae as deposition in growing bones or teeth. Minocycline, related to tetracycline, has also been used in Thailand for the treatment of acute malaria. Vestibular disturbances following the use of minocycline for other diseases have been observed in the U.K.,5 and a high incidence of these side effects has now been signalled in the U.S.A. ${ }^{6}$

There is no doubt that at the present time the best and safest treatment of severe falciparum malaria resistant to 4-aminoquinolines is quinine followed by the combination of sulphadoxine (1-1.5 g) and pyrimethamine $(50-75 \mathrm{mg}$ ) and I fully endorse the relevant conclusions reached by Colonel Hall and his colleagues in their second paper published in the same issue (p. 15). On the other hand I am not convinced by the argument that quinine is more effective than ahloroquine against African strains of $P$. falciparum and believe that until there is a definite proof of ohloroquine resistance in Africa the 4-aminoquinolines should maintain their position of being the most reliable drugs for the treatment of acute malaria. There is also much hope that following the completion of clinical trials now in progress ${ }^{7}$ the quinolinemethanol WR 30090 and the phenanthrenemethanol W/R 33063 will soon extend the range of acceptable, active antimalarial compounds. - I am, etc.,

L. J. BRUCE-ChWATt Wellcome Museum of Medical Science,

London N.W.1

1 Miller, L. H. et al., American fournal of Tropical Medicine and Hygiene, 2 British Medical foumal, $R$, fourmal of the American Medical Association, $1972,220,684$.

4 Rieckmann, K. H., Willerson, D. D., Carson,

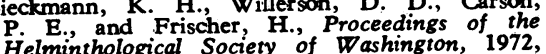
39. 339.

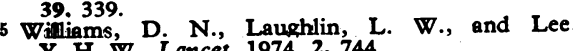
Y. H. W., Lancet, 1974, 2,744. Morbidity and
Center for Disease Control, Mats Center for Disease Control, Morbidity and
Mortality Weekly Report, 1975,24 , 9 . Segal, H. E., et al., American Yournal
Medicine and Hygiene, 1974, 23, 560. 